Original Research

\title{
Optimizing Three Kinds of Coagulants Using Plackett-Burman and Response Surface Methodology for Phosphorus Removal from Domestic Sewage
}

\author{
Longhui Wang ${ }^{1-3}$, Yangwu Chen ${ }^{4}$, Lian Jiang ${ }^{1-3}$, Houzhen Zhou ${ }^{1,2}$, \\ Zhouliang Tan ${ }^{1,2 *}$, Shizhang $\mathrm{Du}^{3}$ \\ ${ }^{1}$ Key Laboratory of Environmental and Applied Microbiology, Chengdu Institute of Biology, \\ Chinese Academy of Sciences, Chengdu, P.R. China \\ ${ }^{2}$ Environmental Microbiology Key Laboratory of Sichuan Province, Chengdu Institute of Biology, \\ Chinese Academy of Sciences, Chengdu, P.R. China \\ ${ }^{3}$ Mianyang Normal University, Mianyang, P.R. China \\ ${ }^{4}$ University of Chinese Academy of Sciences, Beijing, P.R. China
}

Received: 16 October 2017

Accepted: 10 February 2018

\begin{abstract}
This study compounds three types of coagulants $\left(\mathrm{AlCl}_{3}, \mathrm{FeCl}_{3}, \mathrm{Fe}_{2}\left(\mathrm{SO}_{4}\right)_{3}\right)$ with promising effects on TP removal of domestic sewage. The optimum conditions for TP removal using ${ }^{1}$ compounded coagulants are determined by Plackett-Burman (P-B) design, steepest ascent, and Box-Behnken design. The adequacy of the quadratic regression model is evaluated by analysis of variance (ANOVA). Results show that initial $\mathrm{pH}, \mathrm{AlCl}_{3}$, and $\mathrm{Fe}_{2}\left(\mathrm{SO}_{4}\right)_{3}$ are the significant factors for TP removal. F-test, P-value (Prob $>\mathrm{F}$ ), coefficients $\mathrm{R}^{2}$, coefficient of variation, and adequate precision analysis demonstrated the goodness of fit for the regression model. The optimized conditions for TP removal determined by the response surface methodology are initial $\mathrm{pH} 5.2, \mathrm{AlCl}_{3} 45 \mathrm{mg} / \mathrm{L}$, and $\mathrm{Fe}_{2}\left(\mathrm{SO}_{4}\right)_{3} 51 \mathrm{mg} / \mathrm{L}$, respectively. The experimental TP removal efficiency $(82.89 \%)$ agrees with the predicted response value $(81.99 \%)$, thereby validating the feasibility of the model. Compared to single coagulants $\left(\mathrm{AlCl}_{3}, \mathrm{FeCl}_{3}, \mathrm{Fe}_{2}\left(\mathrm{SO}_{4}\right)_{3}\right)$, the compounded coagulants demonstrate $3.29 \%, 7.59 \%$, and $15.19 \%$ higher for TP removal; and $10.1 \%, 3.0 \%$, and $10.3 \%$
\end{abstract}

*e-mail: 46896545@qq.com

Longhui Wang and Yangwu Chen contributed equally to this work. 
higher for $\mathrm{COD}_{\mathrm{Cr}}$ removal. In addition, the compounded coagulants also alleviate the potential hazards to human health due to the dosage decrease of aluminium salt coagulants.

Keywords: domestic sewage, phosphorus removal, Plackett-Burman, response surface methodology

\section{Introduction}

In recent years, the total discharge of domestic sewage in rural areas is increasing all over the world. Many rural areas lack sewage treatment facilities, which leads to a large amount of domestic sewage directly entering local water bodies without any treatment. For example, in the remote areas of Iran, less than $0.2 \%$ of the residents have a sanitary wastewater treatment system [1]. Paruch and Maehlum et al. (2011) pointed out that in rural areas of Norway, only $12 \%$ of the wastewater was collected and only $4 \%$ was treated [2]. At present, the domestic sewage treatment in rural areas of China is less than $30 \%$. Gao et al. (2012) pointed out that the rural areas, which account for nearly $90 \%$ of the land area of China, lack drainage and sewage treatment facilities. About $96 \%$ of rural village sewage directly enters the water bodies, and more than 100 million people suffer from drinking water pollution [3]. It is well known that human excrement, detergents, and other materials in domestic sewage contain large amounts of phosphorus. According to related studies, phosphorus content in water that exceeds $0.02 \mathrm{mg} / \mathrm{L}$ will cause eutrophication pollution [4], which not only threatens aquatic organisms but also affects human health.

The current treatment methods for phosphorus wastewater mainly include biological treatment, chemical precipitation, artificial wetlands, adsorption, crystallization, and the ion exchange method, etc. Specifically, chemical precipitation, is widely used for wastewater phosphorus removal due to its high phosphorus removal efficiency and simple operation, as well as high impact resistance. However, it still encounters several drawbacks, such as large dosage consumption, high cost, and secondary contamination. Accordingly, current research concentrates on developing phosphorus removal coagulants and optimizing technical parameters [5-8]. The measures mentioned above evidently reduced coagulants dosage, production cost, and increased phosphorus removal effects. However, coagulant performance was affected by many factors, hence it was really a problem how to simply and quickly screen key influencing factors and make further optimization. When a great number of process parameters are involved, the statistics-based experimental designs are usually used in different fields, such as agriculture, biochemistry, or medicine [9-10]. Therefore, a statistical method is the first choice in terms of optimization.

A Plackett-Burman (P-B) experiment is able to identify major factors among multiple technical variables, thus eliminating insignificant variables and further optimizing the significant variables [9]. In the steepest ascent method, the gradient direction of the experimental value is taken as the ascent direction, and the variable step is determined based on the value of every factor, thereby rapidly and economically approaching the optimal value [11]. Furthermore, the response surface methodology (RSM) is effective for identifying the optimal conditions for a multi-variable system [12]. At present, the application of the RSM for coagulant optimization is mainly focused on single coagulants such as poly-aluminum chloride [13] and $\mathrm{Al}_{2}\left(\mathrm{SO}_{4}\right)_{3}$ [14]. It is noteworthy that the use of a combination of P-B screening, steepest ascent, and RSM for compounded coagulants optimization has not yet been well documented.

Based on the preliminary results of single-factor experiments from our group, three types of coagulants with promising effects on $\mathrm{COD}_{\mathrm{Cr}}$ and $\mathrm{TP}$ removal were compounded. P-B screening was used to determine the major factors influencing coagulant compounding. RSM was performed to further optimize the key factors for the compounding of three coagulants, thereby enabling the application of the compounded coagulants in TP removal and $\mathrm{COD}_{\mathrm{Cr}}$ removal for rural domestic sewage.

\section{Material and Methods}

\section{Raw Wastewater}

Raw wastewater was taken from a wastewater intake of Chengdu Branch, Chinese Academy of Sciences, and the $\mathrm{COD}_{\mathrm{Cr}}$ value ranged $426-626 \mathrm{mg} / \mathrm{L}$; TP ranged 8.9-11.2 $\mathrm{mg} / \mathrm{L}$. The values of COD and TP concentration of the raw wastewater used in this study were $536 \pm 20 \mathrm{mg} / \mathrm{L}$ and $9.0 \pm 0.2 \mathrm{mg} / \mathrm{L}$, respectively.

\section{Chemicals}

$\mathrm{AlCl}_{3}$ ( $\geq 99 \%$ purity) was purchased from Tianjin Kemiou Chemical Reagent Co., Ltd., China ; $\mathrm{FeCl}_{3}(\geq 97 \%$ purity) was purchased from Tianjin Meilin trade Co., Ltd., China ; and $\mathrm{Fe}_{2}\left(\mathrm{SO}_{4}\right)_{3}(\geq 99 \%$ purity) was purchased from Aladdin Industrial Corporation in Shanghai, China. Other chemicals were all purchased from China.

\section{Experimental Procedure}

Based on the single-factors experimental results, $1000 \mathrm{~mL}$ of raw wastewater was added into a 1-L beaker, and liquid coagulants of $\mathrm{AlCl}_{3}, \mathrm{FeCl}_{3}$, and $\mathrm{Fe}_{2}\left(\mathrm{SO}_{4}\right)_{3}$ were added for TP and CODcr removal. The following reaction conditions were employed: rapid stirring $(350 \mathrm{rpm})$ time $30 \mathrm{~s}$, medium stirring speed 120-150 rpm, medium stirring time $15 \mathrm{~min}$, and settling time $30 \mathrm{~min}$. The initial $\mathrm{pH}$ of the wastewater was 
Table 1. Range of different factors investigated by the P-B design.

\begin{tabular}{|c|c|c|c|}
\hline \multirow{2}{*}{ Symbols } & \multirow{2}{*}{ Variables } & \multicolumn{2}{|c|}{ Levels } \\
\cline { 3 - 4 } & & -1 & 1 \\
\hline $\mathrm{X}_{1}$ & $\mathrm{AlCl}_{3}(\mathrm{mg} / \mathrm{L})$ & 33 & 44 \\
\hline $\mathrm{X}_{2}$ & $\mathrm{FeCl}_{3}(\mathrm{mg} / \mathrm{L})$ & 33 & 44 \\
\hline $\mathrm{X}_{3}$ & $\mathrm{Fe}_{2}\left(\mathrm{SO}_{4}\right)_{3}(\mathrm{mg} / \mathrm{L})$ & 33 & 44 \\
\hline $\mathrm{X}_{4}$ & $\mathrm{pH}$ & 5 & 7 \\
\hline $\mathrm{X}_{5}$ & Rapid stirring $(350 \mathrm{rpm})$ time $(\mathrm{s})$ & 30 & 60 \\
\hline $\mathrm{X}_{6}$ & Medium stirring speed (rpm) & 120 & 150 \\
\hline $\mathrm{X}_{7}$ & Settling time (min) & 30 & 40 \\
\hline $\mathrm{X}_{8}$ & Medium stirring time (min) & 15 & 20 \\
\hline $\mathrm{X}_{9}$ & Virtual factors & $/$ & $/$ \\
\hline
\end{tabular}

adjusted with $\mathrm{H}_{2} \mathrm{SO}_{4}(1 \mathrm{~mol} / \mathrm{L})$ or $\mathrm{NaOH}(1 \mathrm{~mol} / \mathrm{L})$, according to the experimental requirement. After that, the supernatant of wastewater was sampled for determining TP and CODcr. Throughout the experimental period, the stirring operation was performed by a coagulation test agitator Jar Tester (ZR4-6) from Zhongrun Water Co., Ltd., China.

\section{Plackett-Burman Design}

According to the literature [15] and the single factors experiment results, the critical parameters that affect phosphorus removal were screened by P-B design.

In the present study, 12 groups of experiments were conducted with eight variables $\left(\mathrm{AlCl}_{3}, \mathrm{FeCl}_{3}, \mathrm{Fe}_{2}\left(\mathrm{SO}_{4}\right)_{3}\right.$, $\mathrm{pH}$, mixing time, stirring speed, settling time, and stirring time) using P-B design. The variables, low (-1) and high $(+1)$ levels were shown in Table 1 . The regression analysis was carried by (SPSS) software, and the model was as follows:

$$
\begin{aligned}
Y= & \beta_{0}+\beta_{1} X_{1}+\beta_{2} X_{2}+\beta_{3} X_{3}+\beta_{4} X_{4} \\
& +\beta_{5} X_{5}+\beta_{6} X_{6}+\beta_{7} X_{7}+\beta_{8} X_{8}
\end{aligned}
$$

...where $\mathrm{Y}$ represents response values (the removal efficiency of TP and $\mathrm{COD}_{\mathrm{Cr}}$ ); $\beta_{0} \beta_{1} \beta_{2} \beta_{3} \beta_{4} \beta_{5} \beta_{6}, \beta_{7}$, and $\beta_{8}$ represent regression coefficient; and $X_{1}, X_{2}, X_{3}, X_{4}, X_{5}$, $\mathrm{X}_{6}, \mathrm{X}_{7}$, and $\mathrm{X}_{8}$ represent the code value of the variable.

\section{Path of the Steepest Ascent Experiments}

The regression equation of RSM can reflect the fully approximate real situation only when the variables in the neighborhood regions close to the highest point of the response surface. Hence, the central point of actual levels of variables should be determined before conducting the Box-Behnken experiments. Based on P-B experimental results, the path of the steepest ascent experiment was performed. The direction change and the step size range were designed as shown in Table 5.

\section{Box-Behnken Design}

Response surface nethodology (RSM) was applied to optimize the three most significant factors $\left(\mathrm{pH}, \mathrm{AlCl}_{3}\right.$, and $\left.\mathrm{Fe}_{2}\left(\mathrm{SO}_{4}\right)_{3}\right)$ identified by the P-B design. A set of 17 experiments was performed using the Box-Behnken design (Table 6). A second-order polynomial model fitted to the experimental data was developed and could be described by the following equation:

$$
\begin{gathered}
\mathrm{R}(\%)=\beta_{0}+\beta_{1} \mathrm{~A}+\beta_{2} \mathrm{~B}+\beta_{3} \mathrm{C}+\beta_{11} \mathrm{~A}^{2} \\
+\beta_{22} \mathrm{~B}^{2}+\beta_{33} \mathrm{C}^{2}+\beta_{12} \mathrm{AB}+\beta_{13} \mathrm{AC}+\beta_{23} \mathrm{BC}
\end{gathered}
$$

\begin{tabular}{|c|c|c|c|c|c|c|c|c|c|c|c|}
\hline Run & $\mathrm{X}_{1}$ & $\mathrm{X}_{2}$ & $\mathrm{X}_{3}$ & $\mathrm{X}_{4}$ & $\mathrm{X}_{5}$ & $\mathrm{X}_{6}$ & $\mathrm{X}_{7}$ & $\mathrm{X}_{8}$ & $\mathrm{X}_{9}$ & TP removal efficiency $(\%)$ & $\mathrm{COD}_{\mathrm{Cr}}$ removal efficiency (\%) \\
\hline 1 & 1 & -1 & 1 & 1 & -1 & 1 & 1 & 1 & -1 & 60 & 32.2 \\
\hline 2 & -1 & 1 & 1 & 1 & -1 & -1 & -1 & 1 & -1 & 55 & 36.1 \\
\hline 3 & -1 & -1 & -1 & -1 & -1 & -1 & -1 & -1 & -1 & 68 & 56.3 \\
\hline 4 & -1 & -1 & 1 & -1 & 1 & 1 & -1 & 1 & 1 & 75 & 52 \\
\hline 5 & -1 & 1 & 1 & -1 & 1 & 1 & 1 & -1 & -1 & 81 & 53.5 \\
\hline 6 & 1 & 1 & 1 & -1 & -1 & -1 & 1 & -1 & 1 & 85 & 59.7 \\
\hline 7 & 1 & -1 & -1 & -1 & 1 & -1 & 1 & 1 & -1 & 78 & 58.5 \\
\hline 8 & 1 & 1 & -1 & 1 & 1 & 1 & -1 & -1 & -1 & 55 & 28.7 \\
\hline 9 & 1 & 1 & -1 & -1 & -1 & 1 & -1 & 1 & 1 & 75 & 54.6 \\
\hline 10 & 1 & -1 & 1 & 1 & 1 & -1 & -1 & -1 & 1 & 52 & 30.6 \\
\hline 11 & -1 & 1 & -1 & 1 & 1 & -1 & 1 & 1 & 1 & 50 & 35.5 \\
\hline 12 & -1 & -1 & -1 & 1 & -1 & 1 & 1 & -1 & 1 & 44 & 33.7 \\
\hline
\end{tabular}

Table 2. P-B experimental design and response values. 
...where $\mathrm{R}$ represents response (namely $\mathrm{TP}$ removal efficiency), $\beta_{0}$ represents the offset term, and $\beta_{i}, \beta_{i j}$, and $\beta_{\mathrm{ij}}$ are the regression coefficients of the first-order main effect, the second-order main effect, and interaction effect, respectively.

\section{Validating the Experimental Model}

The optimized conditions of compounded coagulants for TP removal were determined by the RSM, and the feasibility of the statistical model was validated under optimum conditions. Also, $\mathrm{COD}_{\mathrm{Cr}}$ removal efficiency was investigated. As a control, the removal efficiency of $\mathrm{TP}$ and $\mathrm{COD}_{\mathrm{Cr}}$ with single coagulant alone was evaluated under the same experimental conditions.

\section{Analytical Methods}

$\mathrm{COD}_{\mathrm{Cr}}$ and TP concentration were determined by procedures given in the standard methods [16] and $\mathrm{pH}$ was determined by a portable BJ-260 $\mathrm{pH}$ meter (Shanghai INESA Scientific Instrument Co., Ltd., China). The calculation and statistical analysis were performed using (SPSS) 19.0, Origin 7.5, and Design-Expert 8.05 software.

\section{Results and Discussion}

\section{Screening of Significant Variables Using P-B Design}

Three out of eight variables - namely $\mathrm{FeCl}_{3}, \mathrm{Fe}_{2}\left(\mathrm{SO}_{4}\right)_{3}$ and $\mathrm{pH}-$ are identified as having a significant effect on $\mathrm{TP}$ and $\mathrm{COD}_{\mathrm{Cr}}$ removal efficiency based on P-B experiments. The corresponding responses are shown in Table 2. In terms of $\mathrm{TP}$ and $\mathrm{COD}_{\mathrm{Cr}}$ removal efficiency, regression analysis is performed using SPSS software, and the results are shown in Tables 3 and 4 , respectively. A multiple-variable linear regression equation is obtained. Specifically, the regression equation of TP removal is as follows:

$$
\begin{aligned}
Y & =0.648+0.027 \mathrm{X}_{1}+0.02 \mathrm{X}_{2}+0.032 \mathrm{X}_{3}-0.122 \mathrm{X}_{4} \\
& +0.003 \mathrm{X}_{5}+0.00215 \mathrm{X}_{6}+0.015 \mathrm{X}_{7}+0.007 \mathrm{X}_{8}
\end{aligned}
$$

A P-value less than $0.05(\mathrm{p}=0.018)$ indicates that the model is significant. The correlation coefficient $\mathrm{R}^{2}$ (0.996) and adjusted correlation coefficient (0.978) suggest a high degree of fit of the model. The standard error of the estimate is $2.04 \%$, indicating good reliability and accuracy of the P-B experiment. The regression equation of $\mathrm{COD}_{\mathrm{Cr}}$ is as follows:

$$
\begin{gathered}
Y=0.443-0.002 \mathrm{X}_{1}+0.004 \mathrm{X}_{2}-0.003 \mathrm{X}_{3}- \\
0.115 \mathrm{X}_{4}-0.012 \mathrm{X}_{5}-0.018 \mathrm{X}_{6}+0.012 \mathrm{X}_{7}+0.005 \mathrm{X}_{8}
\end{gathered}
$$

Table 3. Regression analysis of TP removal.

\begin{tabular}{|c|c|c|c|}
\hline Symbols & DF & t value & P value \\
\hline $\mathrm{X}_{1}$ & 1 & 4.525 & $0.046^{*}$ \\
\hline $\mathrm{X}_{2}$ & 1 & 3.394 & 0.077 \\
\hline $\mathrm{X}_{3}$ & 1 & 5.374 & $0.033^{*}$ \\
\hline $\mathrm{X}_{4}$ & 1 & -20.648 & $0.002^{* *}$ \\
\hline $\mathrm{X}_{5}$ & 1 & 0.566 & 0.629 \\
\hline $\mathrm{X}_{6}$ & 1 & 0.283 & 0.804 \\
\hline $\mathrm{X}_{7}$ & 1 & 2.546 & 0.126 \\
\hline $\mathrm{X}_{8}$ & 1 & 1.131 & 0.375 \\
\hline $\mathrm{X}_{9}$ & 1 & -2.263 & 0.152 \\
\hline Model & 9 & & $0.018^{*}$ \\
\hline Residual & 2 & & \\
\hline Sum & 11 & & \\
\hline
\end{tabular}

Note: ${ }^{*}$ significant $(\mathrm{p}<0.05) ;{ }^{* *}$ extremely significant $(\mathrm{p}<0.01)$

A P-value less than $0.05(\mathrm{p}=0.01)$ indicates that the model is significant. The correlation coefficient $\mathrm{R}^{2}$ and adjusted correlation coefficient are 0.998 and 0.988 respectively, which suggest a high degree of fit of the model. The standard error of the estimate is $1.33 \%$, indicating the good reliability and accuracy of the P-B experiments.

A P-value less than 0.05 indicates a significant influence of the factors on $\mathrm{TP}$ and $\mathrm{COD}_{\mathrm{Cr}}$ removal, and that they can be used for further optimization. From the regression analysis shown in Table 3, it can be seen that $\mathrm{pH}(0.002)$ is the most significant factor for TP removal; followed by $\mathrm{Fe}_{2}\left(\mathrm{SO}_{4}\right)_{3},(0.033)$, and

Table 4. Regression analysis of $\mathrm{COD}_{\mathrm{Cr}}$ removal.

\begin{tabular}{|c|c|c|c|}
\hline Symbols & DF & t value & P value \\
\hline $\mathrm{X}_{1}$ & 1 & -0.606 & 0.606 \\
\hline $\mathrm{X}_{2}$ & 1 & 1.038 & 0.408 \\
\hline $\mathrm{X}_{3}$ & 1 & -0.692 & 0.560 \\
\hline $\mathrm{X}_{4}$ & 1 & -29.802 & $0.001^{* *}$ \\
\hline $\mathrm{X}_{5}$ & 1 & -2.985 & 0.096 \\
\hline $\mathrm{X}_{6}$ & 1 & -4.758 & $0.041^{*}$ \\
\hline $\mathrm{X}_{7}$ & 1 & 3.201 & 0.085 \\
\hline $\mathrm{X}_{8}$ & 1 & 1.384 & 0.301 \\
\hline $\mathrm{X}_{9}$ & 1 & 0.173 & 0.879 \\
\hline Model & 9 & & $0.010^{*}$ \\
\hline Residual & 2 & & \\
\hline Sum & 11 & & \\
\hline
\end{tabular}

Note: * significant $(\mathrm{p}<0.05) ;{ }^{* *}$ extremely significant $(\mathrm{p}<0.01)$ 
Table 5. Design and results of steepest ascent experiments.

\begin{tabular}{|c|c|c|c|c|}
\hline $\begin{array}{c}\text { Run } \\
\text { order }\end{array}$ & $\begin{array}{c}\mathrm{AlCl}_{3} \\
(\mathrm{mg} / \mathrm{L})\end{array}$ & $\begin{array}{c}\mathrm{Fe}_{2}\left(\mathrm{SO}_{4}\right)_{3} \\
(\mathrm{mg} / \mathrm{L})\end{array}$ & $\mathrm{pH}$ & $\begin{array}{c}\text { TP removal } \\
\text { efficiency }(\%)\end{array}$ \\
\hline 1 & 39 & 39 & 7 & 51.7 \\
\hline 2 & 41 & 42 & 6.5 & 54.9 \\
\hline 3 & 43 & 45 & 6 & 73.5 \\
\hline 4 & 45 & 48 & 5.5 & 81.3 \\
\hline 5 & 47 & 51 & 5 & 79 \\
\hline
\end{tabular}

$\mathrm{AlCl}_{3}$ (0.046). Among the three variables, $\mathrm{pH}$ has a negative effect on TP removal, while an increase of $\mathrm{AlCl}_{3}$ and $\mathrm{Fe}_{2}\left(\mathrm{SO}_{4}\right)_{3}$ concentration shows positive effects on TP removal. From Table 4 it can be observed that the main factor influencing $\mathrm{COD}_{\mathrm{Cr}}$ removal is $\mathrm{pH}(0.001)$, followed by stirring speed (0.041). Both factors show negative effects, and a low level of each factor would benefit $\mathrm{COD}_{\mathrm{Cr}}$ removal. Since the present study primarily focuses on TP removal, therefore, the variable stirring speed is excluded. All factors with insignificant effects on TP and $\mathrm{COD}_{\mathrm{Cr}}$ removal are neglected. RSM design is then performed so as to further determine the optimal $\mathrm{pH}, \mathrm{AlCl}_{3}$, and $\mathrm{Fe}_{2}\left(\mathrm{SO}_{4}\right)_{3}$ concentrations. Taking the removal efficiency of $\mathrm{TP}, \mathrm{COD}_{\mathrm{Cr}}$, and economic cost of coagulants into consideration, the following experimental conditions were employed: mixing time of $30 \mathrm{~s}$, rotating speed $120 \mathrm{r} / \mathrm{min}$, stirring period of $15 \mathrm{~min}$, settling time of $30 \mathrm{~min}$, and $\mathrm{FeCl}_{3}$ dosage of $44 \mathrm{mg} / \mathrm{L}$.

\section{Center Point Determination Using the Steepest Ascent Design}

From Table 5, it is obvious that experiment No. 4 shows a higher TP removal efficiency than Nos. 3 and 5. The relatively low TP removal efficiency of experiment No. 3 may be due to the insufficient dosage of coagulants and non-ideal initial $\mathrm{pH}$ for $\mathrm{TP}$ removal. In terms of experiment No. 5, although the amount of coagulants is larger than in No. 4, single-factor analysis shows that $\mathrm{AlCl}_{3}$ and $\mathrm{Fe}_{2}\left(\mathrm{SO}_{4}\right)_{3}$ exhibited poor $\mathrm{TP}$ removal performance under low $\mathrm{pH}$ conditions (data not shown). Therefore, the optimal conditions for TP removal using compounded coagulants should be between Nos. 3 and 5 .

Table 6. Coded levels of three independent variables and Box-Behnken design matrix.

\begin{tabular}{|c|c|c|c|c|}
\hline \multirow{2}{*}{ Factors } & \multirow{2}{*}{ Variables } & \multicolumn{3}{|c|}{ Levels } \\
\hline & & -1 & 0 & 1 \\
\hline A & Initial $\mathrm{pH}$ & 5 & 5.5 & 6 \\
\hline B & $\mathrm{AlCl}_{3}(\mathrm{mg} / \mathrm{L})$ & 43 & 45 & 47 \\
\hline $\mathrm{C}$ & $\mathrm{Fe}_{2}\left(\mathrm{SO}_{4}\right)_{3}(\mathrm{mg} / \mathrm{L})$ & 45 & 48 & 51 \\
\hline \multirow{2}{*}{ Run order } & \multicolumn{3}{|c|}{ Coded levels of variables } & \multirow{2}{*}{ Response-TP removal efficiency (\%) } \\
\hline & A & $\mathrm{B}$ & $\mathrm{C}$ & \\
\hline 1 & 1 & 0 & -1 & 68.3 \\
\hline 2 & 0 & 0 & 0 & 78.4 \\
\hline 3 & 0 & -1 & 1 & 79.5 \\
\hline 4 & 0 & -1 & -1 & 68.6 \\
\hline 5 & 0 & 0 & 0 & 78.4 \\
\hline 6 & 1 & 0 & 1 & 71.8 \\
\hline 7 & -1 & 0 & 1 & 81.8 \\
\hline 8 & 0 & 0 & 0 & 78.7 \\
\hline 9 & 0 & 0 & 0 & 77.1 \\
\hline 10 & -1 & 1 & 0 & 76.5 \\
\hline 11 & 0 & 0 & 0 & 77 \\
\hline 12 & -1 & -1 & 0 & 75.8 \\
\hline 13 & 1 & 1 & 0 & 70.5 \\
\hline 14 & 1 & -1 & 0 & 70.2 \\
\hline 15 & -1 & 0 & -1 & 70.6 \\
\hline 16 & 0 & 1 & 1 & 82.3 \\
\hline 17 & 0 & 1 & -1 & 76.7 \\
\hline
\end{tabular}


Table 7. Analysis of variance (ANOVA) for the quadratic regression model.

\begin{tabular}{|c|c|c|c|c|c|}
\hline Source & Sum of squares & $\mathrm{DF}$ & Mean square & F value & Prob $>F$ \\
\hline Model & 311.17 & 9 & 34.57 & 15.81 & $0.0007 * *$ \\
\hline A & 71.40 & 1 & 71.40 & 32.66 & $0.0007 * *$ \\
\hline B & 17.70 & 1 & 17.70 & 8.10 & $0.0249 *$ \\
\hline $\mathrm{C}$ & 121.68 & 1 & 121.68 & 55.65 & $0.0001 * *$ \\
\hline $\mathrm{AB}$ & 0.04 & 1 & 0.04 & 0.018 & 0.8962 \\
\hline $\mathrm{AC}$ & 14.82 & 1 & 14.82 & 6.78 & $0.0352 *$ \\
\hline $\mathrm{BC}$ & 7.02 & 1 & 7.02 & 3.21 & 0.1162 \\
\hline $\mathrm{A}^{2}$ & 72.87 & 1 & 72.87 & 33.33 & $0.0007 * *$ \\
\hline $\mathrm{B}^{2}$ & 1.10 & 1 & 1.10 & 0.50 & 0.5020 \\
\hline $\mathrm{C}^{2}$ & 1.70 & 1 & 1.70 & 0.78 & 0.4075 \\
\hline Residual & 15.31 & 7 & 2.19 & & \\
\hline Lack of fit & 12.72 & 3 & 4.24 & 6.55 & 0.0505 \\
\hline \multirow[t]{2}{*}{ Error } & 2.59 & 4 & 0.65 & & \\
\hline & 326.47 & 16 & & & \\
\hline
\end{tabular}

Note: ${ }^{*}$ significant $(\mathrm{p}<0.05) ;{ }^{* *}$ extremely significant $(\mathrm{p}<0.01)$

Experiment No. 4 is then used as the central point of the response surface design.

\section{Optimizing with Box-Behnken Design}

The optimal levels of the three significant variables are determined based on RSM, and the response values (TP removal efficiency) are listed in Table 6. The statistically quadratic regression model for TP removal efficiency (R1) in terms of coded factors is as follows:

$$
\begin{gathered}
\mathrm{R} 1(\%)=77.92-2.99 \mathrm{~A}+1.49 \mathrm{~B}+3.90 \mathrm{C}-0.10 \mathrm{AB} \\
-1.93 \mathrm{AC}-1.33 \mathrm{BC}-4.16 \mathrm{~A}^{2}-0.51 \mathrm{~B}^{2}-0.63 \mathrm{C}^{2}
\end{gathered}
$$

...where $\mathrm{A}, \mathrm{B}$, and $\mathrm{C}$ codes represent the initial $\mathrm{pH}$, $\mathrm{AlCl}_{3}$, and $\mathrm{Fe}_{2}\left(\mathrm{SO}_{4}\right)_{3}$ concentrations, respectively.

In order to identify the quadratic regression model, variance analysis is performed using Design Expert 8.05 software, and the results are shown in Table 7. It can be seen that the model P-value (Prob $>$ F) is 0.0007 , and the lack of fit term P-value is 0.0505, which suggests a significant regression and an insignificant lack of fit for the model. The correlation coefficient $\mathrm{R}^{2}$ (0.9531) of the model shows that $95.31 \%$ variability in the response can be explained by this model. The model coefficient of variation $(\mathrm{CV})$ value is $1.96 \%<10 \%$, indicating that Box-Behnken test has good reliability and accuracy. Adequate precision (Adep) is defined as a measurement of the experimental signal-to-noise ratio [17]; adequate precision exceeded 4 , usually indicating that the model will give reasonable performance in prediction [18]. The test precision is $12.146>4$, suggesting high reliability of the equation and validating the effectiveness of the model for predicting test results [19]. P-value $<0.05$ is considered a significant variable. Specifically, the first-order term A, $\mathrm{B}$, and $\mathrm{C}$, second-order term $\mathrm{A}^{2}$, and interaction term $\mathrm{AC}$ are significant variables, while $\mathrm{AB}, \mathrm{BC}, \mathrm{B}^{2}$, and $\mathrm{C}^{2}$ are not significant. The optimal conditions for TP removal predicted by the regression model are $\mathrm{AlCl}_{3} 45 \mathrm{mg} / \mathrm{L}$, $\mathrm{Fe}_{2}\left(\mathrm{SO}_{4}\right)_{3} 51 \mathrm{mg} / \mathrm{L}$, and $\mathrm{pH} 5.2$, respectively.

Response surface graphs based on the fitted quadratic polynomial equation are plotted to reveal the relationship between variables $\mathrm{AlCl}_{3}, \mathrm{Fe}_{2}\left(\mathrm{SO}_{4}\right)_{3}, \mathrm{pH}$, and the response (TP removal efficiency). Results show that initial $\mathrm{pH}$, $\mathrm{AlCl}_{3}$ concentration, and $\mathrm{Fe}_{2}\left(\mathrm{SO}_{4}\right)_{3}$ concentration are key factors for TP removal of domestic sewage. Keeping the $\mathrm{Fe}_{2}\left(\mathrm{SO}_{4}\right)_{3}$ coding value as 0 makes the initial $\mathrm{pH}$ and $\mathrm{AlCl}_{3}$ coding values vary in the range of $(-1,1)$, their influence on TP removal efficiency is shown in Fig. 1a). When the $\mathrm{pH}$ coding value is between -1 and 0 , i.e., $\mathrm{pH}$ between 5 and 5.5, the TP removal efficiency increased with increasing $\mathrm{pH}$ and slightly decreased when the $\mathrm{pH}$ is above 5.5. According to the multi-order binomial regression equation obtained from the response surface model, $\mathrm{AB}$ has negative effects $(-0.1 \mathrm{AB})$ on TP removal. When $\mathrm{pH}$ exceeded a certain range, the removal effects decreased. Therefore, with a $\mathrm{pH}$ coding value within $(-1,0)$ and $\mathrm{AlCl}_{3}$ within $(0,1)$, an increase of $\mathrm{AlCl}_{3}$ concentration is beneficial for TP removal.

When the coding value of $\mathrm{AlCl}_{3}$ is 0 , the influences of initial $\mathrm{pH}$ and $\mathrm{Fe}_{2}\left(\mathrm{SO}_{4}\right)_{3}$ on $\mathrm{TP}$ removal and their interaction are shown in Fig. 1b). As $\mathrm{pH}$ increased from 5 to 5.5, TP removal efficiency increased with increasing $\mathrm{Fe}_{2}\left(\mathrm{SO}_{4}\right)_{3}$ concentration and then declined when $\mathrm{pH}$ exceeded 5.5. The P-B experimental results indicate that 

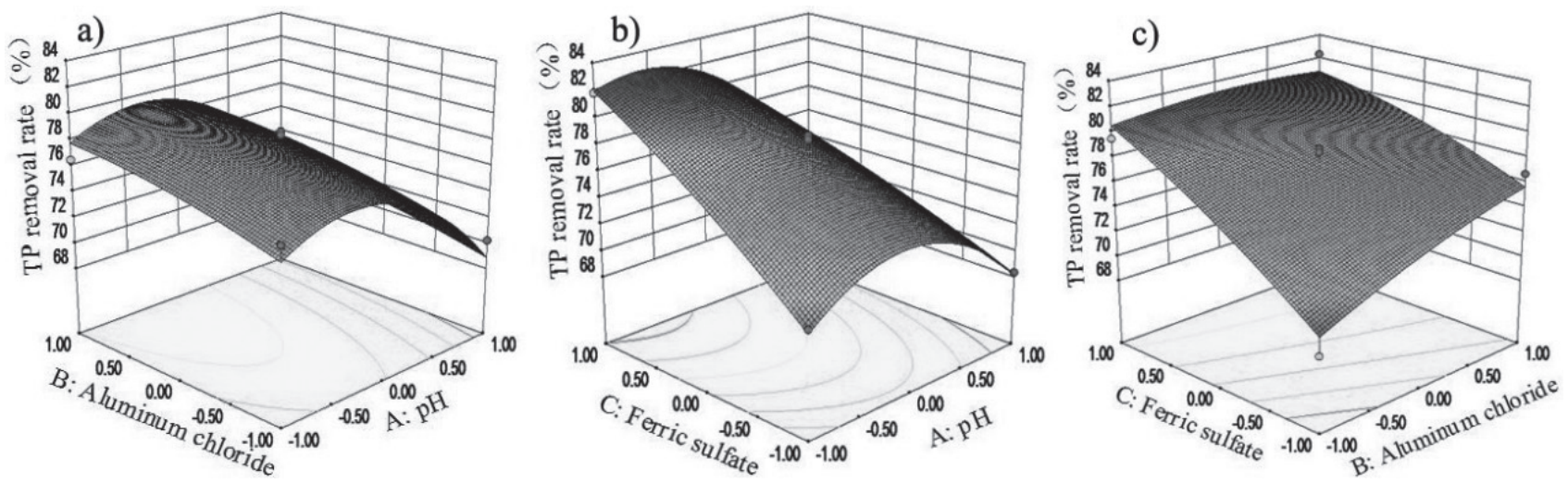

Fig. 1. Three-dimensional response surface plots for TP removal: a) effect of aluminum chloride dosage and initial $\mathrm{pH}$ on TP removal, b) effect of ferric sulfate dosage and initial $\mathrm{pH}$ on TP removal, and c) effect of ferric sulfate dosage and aluminum chloride dosage on TP removal.

initial $\mathrm{pH}(\mathrm{A})$ and $\mathrm{Fe}_{2}\left(\mathrm{SO}_{4}\right)_{3}(\mathrm{C})$ play a significant role on TP removal and $\mathrm{pH}(\mathrm{A})>\mathrm{Fe}_{2}\left(\mathrm{SO}_{4}\right)_{3}(\mathrm{C})$. According to the multi-order binomial regression equation obtained from the response surface model, AC (-1.93) has a negative effect on TP removal. It can be speculated that, in order to improve TP removal efficiency, the first choice should be reducing the initial $\mathrm{pH}$ of the sewage. Hence, increasing $\mathrm{Fe}_{2}\left(\mathrm{SO}_{4}\right)_{3}$ concentration can promote TP removal when keeping the initial $\mathrm{pH}$ of sewage at 5.5 .

Fig. 1c) shows the influence of $\mathrm{Fe}_{2}\left(\mathrm{SO}_{4}\right)_{3}$ and $\mathrm{AlCl}_{3}$ on TP removal when the $\mathrm{pH}$ coding value was 0 . With $\mathrm{pH}$ at 5.5, TP removal efficiency increased gently with an increase in the two types of coagulants. Different coagulants have various performances for TP removal. As reported, the two types of coagulants would be hydrolyzed into different polynuclear hydroxyl complexes in aqueous solution with long line shape structures. For example, $\mathrm{Fe}_{2}(\mathrm{OH})_{2}{ }^{4+}, \mathrm{Fe}_{3}(\mathrm{OH})_{4}{ }^{5+}, \mathrm{Fe}_{5}(\mathrm{OH})_{9}{ }^{5+}$, and $\mathrm{Fe}_{5}(\mathrm{OH})_{8}{ }^{7+}$ formed by hydrolysis of ferric salts [20], and mononuclear complex $\mathrm{Al}(\mathrm{OH})^{+}$formed by hydrolysis of aluminium salts composed a series of polynuclear complexes $\left[\mathrm{Al}_{\mathrm{n}}(\mathrm{OH})_{\mathrm{m}}{ }^{(3 \mathrm{n}-\mathrm{m})+}(\mathrm{n}>1, \mathrm{~m} \leq 3 \mathrm{n})\right]$ through collision [21]. The polynuclear complex plays an important role in TP removal, and hydrolysis of the compounded coagulants could form different kinds of hydroxyl complexes. Therefore, only the two types of coagulants coexist in an appropriate ratio can guarantee positive effects for TP removal. According to the quadratic polynomial, the interaction of two coagulants had negative effects. Therefore, when the $\mathrm{Fe}_{2}\left(\mathrm{SO}_{4}\right)_{3}$ coding value is between 0 and 1 , the $\mathrm{AlCl}_{3}$ should be kept between -1 and 0 .

\section{Validating the Model}

Validating the statistical model and regression equation is conducted with the optimum conditions of $\mathrm{pH} 5.2, \mathrm{AlCl}_{3} 45 \mathrm{mg} / \mathrm{L}, \mathrm{Fe}_{2}\left(\mathrm{SO}_{4}\right)_{3} 51 \mathrm{mg} / \mathrm{L}$, and $\mathrm{FeCl}_{3}$ $44 \mathrm{mg} / \mathrm{L}$. Under optimal conditions, the experimental TP removal rate is $82.89 \%$, which is close to the response prediction of $81.99 \%$. Meanwhile, the $\mathrm{COD}_{\mathrm{Cr}}$ removal rate reaches $51.4 \%$. The results verified the feasibility of the combined application of the P-B test design, steepest ascent design, and the RSM, in comparison with the studies of Xie et al. (2014) [22], Tolkou and Zouboulis (2015) [23], the present study considered more influencing factors on compounded coagulant efficiency, required less work, and was more scientific. Fig. 2 shows that the compounded coagulants have efficient removal
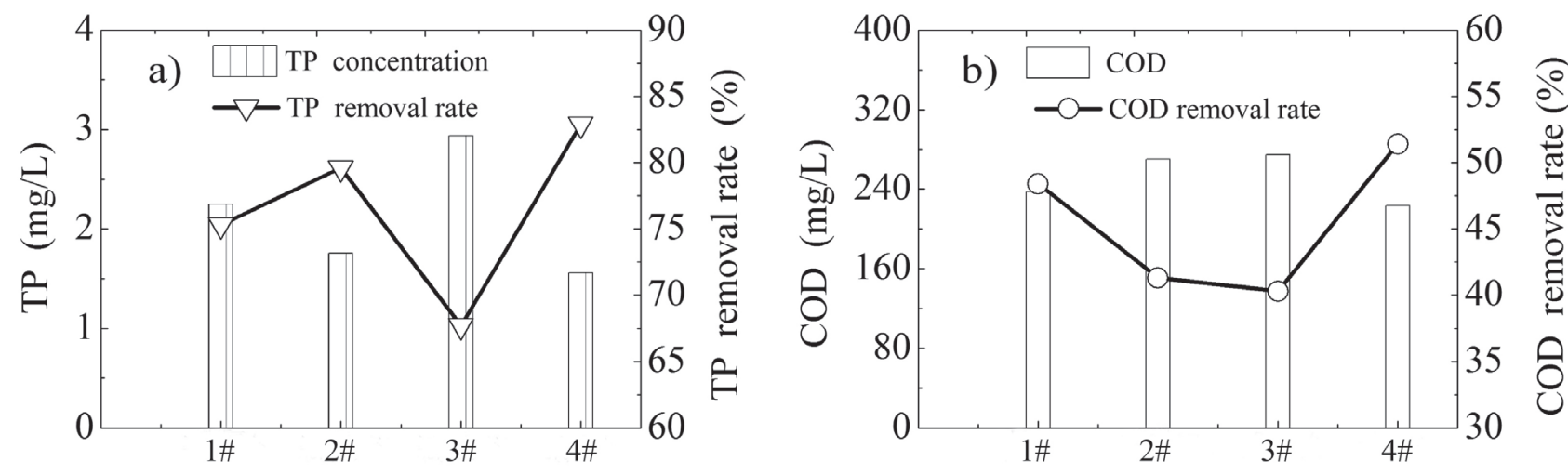

Fig. 2. TP and COD removal efficiencies under single coagulants: 1) Ferric chloride, $\mathrm{FeCl}_{3}$; 2) Aluminum chloride, $\mathrm{AlCl}_{3}$; 3 ) $\mathrm{Ferric}$ sulfate, $\mathrm{Fe}_{2}\left(\mathrm{SO}_{4}\right)_{3}$; and 4) compounded coagulants composed of $\mathrm{AlCl}_{3}, \mathrm{FeCl}_{3}$, and $\mathrm{Fe}_{2}(\mathrm{SO} 4)_{3}$. 
effects for TP and $\mathrm{COD}_{\mathrm{Cr}}$. For the same economic cost, TP removal efficiency using the compounded coagulants is $3.29 \%, 7.59 \%$, and $15.19 \%$ higher than that of the single coagulants of $\mathrm{AlCl}_{3}, \mathrm{FeCl}_{3}$, and $\mathrm{Fe}_{2}(\mathrm{SO} 4)_{3}$, respectively. Similarly, $\mathrm{COD}_{\mathrm{Cr}}$ removal efficiency is $10.1 \%, 3.0 \%$, and $10.3 \%$ higher, respectively. Compared with the results reported by Ding et al. (2012) $\left(1 \mathrm{mg} \mathrm{FeCl}_{3}\right.$ was capable of removing $0.023 \mathrm{mg} \mathrm{TP}$ ) [24], phosphorus removal per unit of compounded coagulants was 2.3 times higher $(0.053 \mathrm{mg})$, and the cost decreased by more than $50 \%$. In addition, a number of researchers have reported that water purification with aluminium salt could cause various diseases [25-28]. Therefore, compared to aluminium salt coagulants, the compounded coagulants, with a small dosage of aluminium salt used, helped to reduce potential threats to human health.

\section{Conclusions}

The aim of this study is to screen and optimize compounded coagulants for TP and $\mathrm{COD}_{\mathrm{Cr}}$ removal of domestic sewage use. Among eight factors, initial $\mathrm{pH}, \mathrm{AlCl}_{3}$, and $\mathrm{Fe}_{2}\left(\mathrm{SO}_{4}\right)_{3}$ were demonstrated to have significant influence on TP removal based on P-B design. The optimum conditions for TP removal were predicted to be initial $\mathrm{pH} 5.2, \mathrm{AlCl}_{3} 45 \mathrm{mg} / \mathrm{L}$, and $\mathrm{Fe}_{2}\left(\mathrm{SO}_{4}\right)_{3}$ $51 \mathrm{mg} / \mathrm{L}$ using Box-Behnken design. The statistical model was validated by experimental results. The removal efficiencies of TP and $\mathrm{COD}_{\mathrm{Cr}}$ by the compounded coagulants were $82.89 \%$ and $51.4 \%$, respectively, under the conditions of $\mathrm{pH} 5.2, \mathrm{AlCl}_{3} 45 \mathrm{mg} / \mathrm{L}, \mathrm{Fe}_{2}\left(\mathrm{SO}_{4}\right)_{3}$ $51 \mathrm{mg} / \mathrm{L}$, and $\mathrm{FeCl}_{3} 44 \mathrm{mg} / \mathrm{L}$.

\section{Acknowledgements}

This work was supported by the Sichuan Key Point Research and Invention Program (2017SZ0179), Science and Technology Service Network Initiative, Chinese Academy of Science (KFJ-SW-STS-175), and Youth Innovation Promotion Association CAS (2016331).

\section{Conflict of Interest}

The authors declare no conflict of interest.

\section{References}

1. FARROKHI M., HAJRASOLIHA M., MEEMARI G., FAHIMINIA M., TALEBI M., KOHANSAL M. The creation of management systems for funding priorities in wastewater project in rural communities in the Islamic Republic of Iran, Water Sci Technol, 58, 1181, 2008.

2. PARUCH A.M., MAEHLUM T., OBARSKAPEMPKOWIAK H., GAJEWSKA M., WOJCIECHOWSKA E., OSTOJSKI. A. Rural domestic wastewater treatment in Norway and Poland: experiences, cooperation and concepts on the improvement of constructed wetland technology, Water Sci Technol, 63, 776, 2011.

3. GAO J.Q., CHEN S.H., WANG W.L., YAN Q.S., JIANG N., ZHANG. R.Q. Effects of Unpowered Complex EcoTechnology on Sewage Purification in Central Chinese Rural Areas, Pol J Environ Stud, 21, 1595, 2012.

4. WU Y., AN S.L. Present and prospects of methods of phosphorus removal from wastewater. Journal of Tianjin Polytechnic University, 20, 74, 2001 [In Chinese].

5. MOUSSAS P.A., ZOUBOULIS. A.I. A new inorganicorganic composite coagulant, consisting of Polyferric Sulphate (PFS) and Polyacrylamide (PAA). Water Res, 43, 3511, 2009.

6. WEI Y.X., DING A.M., DONG L., TANG Y.Q., YU F.L., DONG X.Z. Characterisation and coagulation performance of an inorganic coagulant-poly-magnesium-silicatechloride in treatment of simulated dyeing wastewater. Colloid Surface A, 470, 137, 2015.

7. CARAVELLI A.H., DE GREGORIO C., ZARITZKY N.E. Effect of operating conditions on the chemical phosphorus removal using ferric chloride by evaluating orthophosphate precipitation and sedimentation of formed precipitates n batch and continuous systems. Chem Eng J, 209, 469, 2012.

8. SZABO I., TAKACS MURTHY S., DAIGGER G.T., LICSKO I., SMITH. S. Significance of design and operational variables in chemical phosphorus removal. Water Environment Research, 80, 407-416, 2008.

9. VANAJA. K., SHOBHA RANI R.H. Design of Experiments: Concept and Applications of Plackett Burman Design. Clinical Research and Regulatory Affairs, 24, 1, 2008.

10. ROSA J.L., ROBIN A., NAKAZATO R.Z., RIBEIRO M.B., PIASSA M.P., SILVA M.B. Formation of titania nanotube arrays by anodisation: DOE approach. Surf Eng, 30, 115, 2014.

11. KIRAN B., KAUSHIK A., KAUSHIK C.P. Response surface methodological approach for optimizing removal of $\mathrm{Cr}(\mathrm{VI})$ from aqueous solution using immobilized cyanobacterium. Chem Eng J, 126, 147, 2007.

12. REDDY L.V.A., WEE Y.J., YUN J.S., RYU H.W. Optimization of alkaline protease production by batch culture of Bacillus sp RKY3 through Plackett-Burman and response surface methodological approaches. Bioresource Technol, 99, 2242, 2008.

13. GHAFARI S., AZIZ H.A., ISA M.H., ZINATIZADEH A.A.. Application of response surface methodology (RSM) to optimize, coagulation-flocculation treatment of leachate using poly-aluminum chloride (PAC) and alum. J Hazard Mater, 163, 650, 2009.

14. BASKAN M.B., PALA A.A. statistical experiment design approach for arsenic removal by coagulation process using aluminum sulfate. Desalination, 254, 42, 2010.

15. L.J., W.J.L., FENG. C.M. Analysis on PFS a Coagulant for Phosphorus Removal, Water \& Wastewater 32, 2006 [In Chinese].

16. NEPA C. Water and Wastewater Monitoring Methods. fourth ed., Chinese Environmental Science Publishing Press, Beijing. 2002 [In Chinese].

17. ZAINAL-ABIDEEN M., ARIS A., YUSOF F., ABDULMAJID Z., SELAMAT A., OMAR S.I. Optimizing the coagulation process in a drinking water treatment plant - comparison between traditional and statistical experimental design jar tests. Water Sci Technol 65, 496-, 2012. 
18. CAO X.Z., LOU H.Q., WEI W., ZHU L.J., Treatment of tetrahydrofuran wastewater by the Fenton process: response surface methodology as an optimization tool. Water Sci Technol 69, 1080-, 2014.

19. XIAO G., ZHANG X., SU H.J., TAN T.W. Plate column biosorption of $\mathrm{Cu}(\mathrm{II})$ on membrane-type biosorbent (MBS) of Penicillium biomass: Optimization using statistical design methods. Bioresource Technol 143, 490, 2013.

20. XING W., HUANG W.M., LI D.H., LIU Y.D. Research progress of coagulant ferric salt and iron salt mixing mechanism of phosphorus removal technology. Water \& Wastewater, 32, 88, 2006 [In Chinese].

21. GONG Y.Z., XU J.Y. Experimental study on phosphorus removal from aluminum salt. Shanxi Architecture, 35, 181, 2009 [In Chinese].

22. XIE J., CHENG. Y.J., BI Z., WANG D.S., DUAN J.M. Coagulation of a low temperature and turbidity raw source water by Fe-Al composite coagulants. Journal of Environmental Engineering and Science, 8, 3546, 2014 [In Chinese].

23. TOLKOU A.K., ZOUBOULIS A.I., Synthesis and coagulation performance of composite poly-aluminum- ferric-silicate-chloride coagulants in water and wastewater. Desalin Water Treat, 53, 3309, 2015.

24. DING D.C., ZHOU H.J., WANG Q.Y. Comparative Study on the Phosphorus Removal Effect of Two Frequentlyused Inorganic Coagulating Agent. Guangdong Chemical Industry, 39, 270, 2009 [In Chinese].

25. BONDY S.C., Low levels of aluminum can lead to behavioral and morphological changes associated with Alzheimer's disease and age-related neurodegeneration. Neurotoxicology, 52, 222, 2016.

26. KAWAHARA M., KATO-NEGISHI M. Link between Aluminum and the Pathogenesis of Alzheimer's Disease: The Integration of the Aluminum and Amyloid Cascade Hypotheses. International Journal of Alzheimer's Disease, 2011, 1, 2011.

27. WALTON J.R. Chronic Aluminum Intake Causes Alzheimer's Disease: Applying Sir Austin Bradford Hill's Causality Criteria. J Alzheimers Dis, 40, 765, 2014.

28. BERTHON G. Aluminium speciation in relation to aluminium bioavailability, metabolism and toxicity. Coordination Chemistry Reviews, 228, 319, 2002. 
